Jurnal Insan Farmasi Indonesia, 3(2) Desember 2020 (317-326)

Mochammad Maulidie Alfiannor Saputera

p-ISSN 2621-3184; e-ISSN 2621-4032

doi: 10.36387/jifi.v3i2.599

\title{
SELISIH TARIF RUMAH SAKIT TERHADAP TARIF INA-CBG'S PADA PASIEN SECTIO CAESAREA DI RUMAH SAKIT DAERAH IDAMAN BANJARBARU TAHUN 2019
}

\author{
Mochammad Maulidie Alfiannor Saputera ${ }^{*}$, Ahmad ${ }^{1}$, Anna Khumaira Sari ${ }^{1}$, Ayu \\ Soraya ${ }^{2}$ \\ ${ }^{1}$ Sekolah Tinggi Ilmu Kesehatan ISFI Banjarmasin \\ ${ }^{2}$ Rumah Sakit Daerah Idaman Banjarbaru \\ : mochammadsaputera16@gmail.com
}

\begin{abstract}
ABSTRAK
Angka operasi caesar terus meningkat di setiap negara, World Health Organization (WHO) merekomendasikan Caesarean Section Rate (CSR) yang ideal bagi suatu negara berkisar 10\% sampai 15\%. INA-CBG's merupakan pembayaran dengan sistem paket berdasarkan penyakit yang diderita pasien. Dalam penerapan sistem INA-CBG's sering terjadi permasalahan dalam pembiayaanya. Hal yang sering terjadi adalah besarnya tarif rumah sakit pada prosedur Sectio Caesarea melebihi klaim INA-CBG's. Penelitian ini bertujuan untuk mengetahui selisih antara tarif rumah sakit dengan klaim INA-CBG's di RSD idaman Banjarbaru. Penelitian ini merupakan penelitian observasional rumah sakit terhadap biaya medis langsung (direct medical cost), data diambil secara retrospektif dari data klaim peserta JKN pasien Sectio Caesarea tahun 2019 di RSD Idaman Banjarbaru sebanyak 833 sampel data menggunakan sampel jenuh. Perhitungan data untuk mengetahui selisih dilakukan dengan cara mengurangkan tarif rumah sakit dengan tarif INA-CBG's. Hasil penelitian menunjukkan selisih antara tarif rumah sakit dengan tarif INA-CBG's pada pasien Sectio Caesarea di RSD Idaman Banjarbaru adalah selisih negatif sebesar Rp.3.908.338.992 ( $\mathrm{n}=833$ ) dan selisih rata-rata tarif rumah sakit dengan rata-rata tarif INA-CBG's adalah Rp.4.691.884 per pasiennya.
\end{abstract}

Kata Kunci: Selisih tarif, Sectio Cesarea, Tarif Rumah Sakit.

ABSTRACT

Caesar's operating rate continues to increase in every country, the World Health Organization (WHO) recommends the ideal Caesarean Section Rate (CSR) for a country is around 10\% to 15\%. INA-CBG's is a payment with a package system based on the patient's illness. In implementing the INA-CBG's system, problems often occur in the financing. The thing that often happens is hospital rates in the Caesarean Sectio exceed INA-CBG's claims. The study aims to determine the difference between hospital rates with claims of INA-CBG's in Idaman Hospital Banjarbaru. This study is an observational hospital study of direct medical costs, data retrieved retrospectively from the JKN participant claims data of patients with Sectio Caesarea in 2019 in Hospital Idaman Banjarbaru as many as 833 data samples using samples jenuh. Data calculation to find out the difference is done by subtracking hospital rates with INA-CBG's rates. The result showed the difference between hospital rates and INA-CBG's rates in Sectio Caesarea patients in Hospital Idaman Banjarbaru is a negative difference of Rp. 3.908.338.992 
Jurnal Insan Farmasi Indonesia, 3(2) Desember 2020 (317-326)

Mochammad Maulidie Alfiannor Saputera

p-ISSN 2621-3184; e-ISSN 2621-4032

doi: $10.36387 /$ jifi.v3i2.599

$(n=833)$ and the difference between the average hospital rates and the average INA-CBG's rates is Rp.4.691.884 per patient.

Keywords: Difference in Rates, Cesarean Section, Regional Hospital Rates

\section{PENDAHULUAN}

$\begin{array}{rrr} & \text { Melahirkan merupakan } \\ \text { proses akhir dari serangkaian }\end{array}$ kehamilan. Ada dua cara persalinan, yaitu persalinan lewat vagina lebih dikenal dengan persalinan normal atau alami dan persalinan dengan operasi Sectio Caesarea yaitu bayi dikeluarkan lewat pembedahan perut ${ }^{1}$. Saat ini Sectio Caesarea sudah menjadi sesuatu yang umum. Indikasi dilakukannya yang berasal dari ibu yaitu disporposi kepala punggung, disfungsi uterus, dan plasenta previa. Sedangkan yang berasal dari janin yaitu janin besar, gawat janin, dan letak lintang ${ }^{2}$.

\section{WHO (World Health} Organization) menetapkan standar rata-rata Sectio Caesarea di sebuah Negara adalah sekitar 5-15\% per 1000 kelahiran di dunia Rumah sakit pemerintah kira-kira $11 \%$ sementara rumah sakit swasta bisa lebih dari $30 \%{ }^{3}$. Menurut WHO peningkatan Sectio Caesare di seluruh Negara selama tahun 2007 -2008 yaitu
110.000 per kelahiran di seluruh Asia $^{4}$.

Menurut hasil survei global WHO yang dilakukan di beberapa negara Asia di tahun 2007 dan 2008, di Kamboja, China, Nepal, Filipina, Srilangka, Thailand, dan Vietnam diketahui bahwa persentase persalinan caesar sekitar 27,3\%. Survei ini meneliti hampir 108.000 persalinan di 122 rumah sakit.

$\begin{array}{ll}\text { Sectio } & \text { Caesarea dapat } \\ \text { meningkatkan } & \text { morbiditas dan } \\ \text { mortalitas } & \text { maternal, sehingga } \\ \text { seharusnya } & \text { dilakukan hanya }\end{array}$
karena adanya indikasi medis ${ }^{5}$. Persentase persalinan dengan bedah caesar meningkat sebesar $10 \%$ yang awalnya $7 \%$ pada SDKI tahun 2007 menjadi $17 \%$ pada SDKI tahun 2017, dengan persentase persalinan caesar paling banyak terjadi pada wanita yang bersalin saat umur 35-49 tahun (22\%), wanita dengan kelahiran pertama (19\%), wanita yang tinggal di perkotaan (23\%), wanita berpendidikan tinggi dan 
Jurnal Insan Farmasi Indonesia, 3(2) Desember 2020 (317-326)

Mochammad Maulidie Alfiannor Saputera

p-ISSN 2621-3184; e-ISSN 2621-4032

doi: $10.36387 /$ jifi.v3i2.599

berada pada kuintil kekayaan teratas

Populasi dan sampel dalam (masing masing 32\%) .

INA-CBG's merupakan pembayaran dengan sistem "paket", berdasarkan penyakit yang diderita pasien. Rumah Sakit akan mendapatkan pembayaran berdasarkan tarif INA-CBG's yang merupakan rata-rata biaya untuk suatu kelompok diagnosis. Dalam penerapan sistem INA-CBG's ini sering terjadi permasalahan dalam pembiayannya. Hal yang sering terjadi adalah besarnya tarif rumah sakit pada suatu prosedur kesehatan melebihi dari klaim INA-CBG's sehingga menyebabkan sebagian rumah sakit merasa terbebani dengan sistem ini. INA-CBG's ini bertujuan agar seluruh penduduk Indonesia terlindungi dalam sistem asuransi sehingga mereka dapat memenuhi kebutuhan dasar kesehatan?

\section{METODE PENELITIAN}

Penelitian ini dilakukan dari bulan Maret - April 2020 yang dilaksanakan di unit verifikasi JKN (Jaminan Kesehatan Nasional) RSD Idaman Banjarbaru.

HASIL DAN PEMBAHASAN

Karakteristik Sampel 
Jurnal Insan Farmasi Indonesia, 3(2) Desember 2020 (317-326)

Mochammad Maulidie Alfiannor Saputera

p-ISSN 2621-3184; e-ISSN 2621-4032

doi: 10.36387/jifi.v3i2.599

Data klaim pasien peserta

JKN (Jaminan Kesehatan Nasional)

dengan prosedur persalinan Sectio

Caesarea di RSD Idaman Banjarbaru

2019 yaitu sebanyak 833 (delapan

pada bulan Januari 2019 - Desember ratus tiga puluh tiga) dengan kode INA-CBG's O-6-10-I, O-6-10-II, O6-10-III, dapat dilihat pada gambar 1

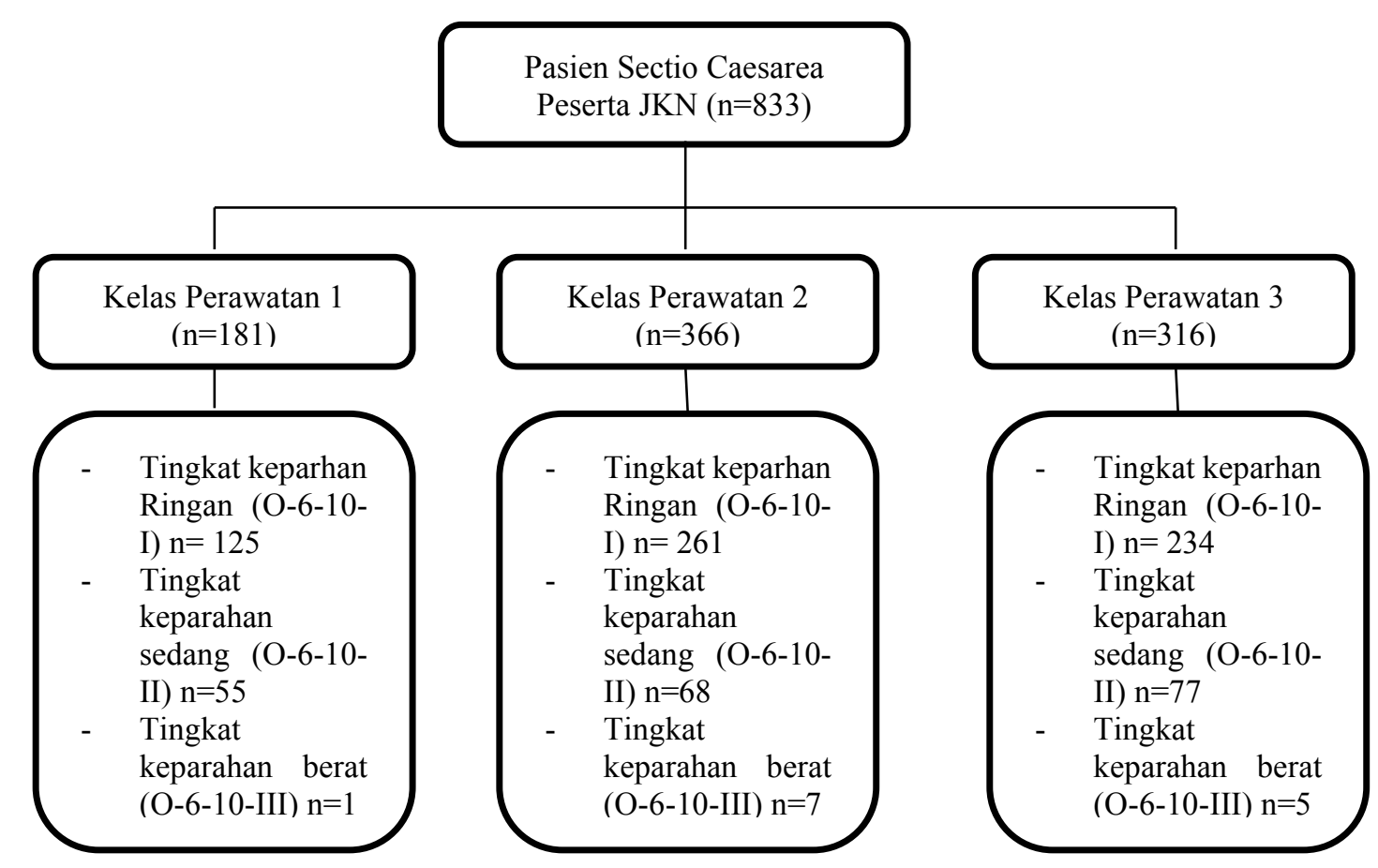

Gambar 1. Bagan Pengambilan Sampel

\section{Karakteristik sampel berdasarkan kepesertaan BPJS}

Tabel 1. Karakteristik berdasarkan kepesertaan BPJS pasien persalinan bedah Sectio Caesarea di RSD Idaman Banjarbaru.

\begin{tabular}{lccc}
\hline \multicolumn{1}{c}{$\begin{array}{c}\text { Sistem } \\
\text { pembayaran }\end{array}$} & Pasien & $\%$ & $\begin{array}{c}\sum \\
\text { Pasien }\end{array}$ \\
\hline $\begin{array}{l}\text { BPJS PBI } \\
\text { BPJS non } \\
\text { PBI }\end{array}$ & 331 & 39,74 & \\
\hline
\end{tabular}

Peserta BPJS terbagi atas 2 kategori yaitu kategori PBI (Penerima Bantuan Iuran) dan non PBI. Berdasarkan hasil dari penelitian pasien persalinan Sectio Caesarea dengan kategori PBI di RSD Idaman Banjarbaru berjumlah 331 dari 833 pasien $(39,74 \%)$ dan kategori non PBI berjumlah 502 dari 833 pasien $(60,26 \%)$. Peserta dengan kategori non PBI bisa memilih kelas perawatan 1, 2 dan 3 sesuai kemampuan peserta dalam membayar iuran di setiap bulannya. Tiap kelas memiliki iuran yang 
Jurnal Insan Farmasi Indonesia, 3(2) Desember 2020 (317-326)

Mochammad Maulidie Alfiannor Saputera

p-ISSN 2621-3184; e-ISSN 2621-4032

doi: $10.36387 /$ jifi.v3i2.599

berbeda-beda tetapi tidak

membedakan pelayanan yang

didapat, yang membedakan pada tiap

kelas perawatan hanya pada kamar

akomodasi saja?

\section{Karakteristik usia pasien}

Karakteristik berdasarkan usia pasien persalinan bedah Sectio Caesarea di RSD Idaman Banjarbaru yang menjalani rawat inap periode tahun 2019 dapat dilihat pada tabel 2 ditujukan untuk mengetahui jumlah pasien direntang usia beserta persentasenya yang menjalani persalinan caesar.

Tabel 2. Karakteristik usia pasien

\begin{tabular}{|c|c|c|c|}
\hline Usia & Jumlah & $\%$ & $\sum$ Pasien \\
\hline$<20$ & 9 & 1,08 & \multirow{4}{*}{833} \\
\hline $20-30$ & 414 & 49,70 & \\
\hline $31-41$ & 370 & 44,42 & \\
\hline$>41$ & 40 & 4,80 & \\
\hline
\end{tabular}

karakteristik usia pasien peserta JKN yang menjalani persalinan Sectio Caesarea di RSD Idaman Banjarbaru pada periode Janurari - Desember 2019, didominasi pada pasien dengan rentang usia $20-30$ tahun dengan jumlah 414 pasien (49,70\%) dari 833 pasien, dan yang terendah yaitu pasien pada rentang

usia $<20$ tahun dengan jumlah hanya 9 pasien $(1,08 \%)$.

Hal ini sesuai dengan penelitian Salfariani $(2012)^{10}$ bahwa kehamilan di usia 20 - 30 tahun adalah usia yang paling tepat bagi wanita untuk mempunyai anak dan merupakan rentang usia yang matang. Sementara jumlah pasien yang terendah yaitu umur 47 tahun 1 pasien $(0,12 \%)$. Berdasarkan penelitian Sibuea dkk (2013) bahwa kehamilan di usia 35 tahun ke atas lebih berisiko tinggi dibandingkan hamil pada usia normal yaitu usia 20 -30 tahun dan bayi yang dilahirkan rentan mengalami kelainan genetik bahkan kematian pada ibu. Oleh karena itu baiknya usia ibu untuk melahirkan berada pada rentang 20 30 tahun $^{11}$.

\section{Karakteristik tingkat keparahan dan kelas perawatan pasien.}

Hasil pada tabel 3 menunjukkan bahwa pasien dengan karakteristik tingkat keparahan didominasi oleh O-6-10-I (ringan) dengan jumlah 620 pasien (74,43\%), yaitu pasien Sectio Caesarea tanpa komplikasi maupun komorbiditi. Karakteristik tingkat keparahan O-6- 
Jurnal Insan Farmasi Indonesia, 3(2) Desember 2020 (317-326)

Mochammad Maulidie Alfiannor Saputera

p-ISSN 2621-3184; e-ISSN 2621-4032

doi: $10.36387 /$ jifi.v3i2.599

10-II (sedang) diketahui berjumlah 200 pasien $(24,01 \%)$, yang merupakan pasien Sectio Caesarea dengan diagnosa sekunder mild komplikasi dan komorbiditi. Sedangkan pada O-6-10-III (berat) hanya berjumlah 13 pasien $(1,56 \%)$ yaitu pasien dengan diagnosa sekunder major komplikasi dan komorbiditi $^{(12)}$.

$$
\text { Pengelompokan tingkat }
$$

keparahan dan kelas perawatan pada penelitian ini dapat dilihat pada tabel 3.

Tabel 3. Karakteristik tingkat keparahan, dan kelas perawatan pasien.

\begin{tabular}{ccccc}
\hline Karakte ristik & Variasi Kelompok & Jumlah Pasien Persentase (\%) & Total \\
\hline \multirow{3}{*}{ Tingkat Keparahan } & O-6-10-I & 620 (Ringan) & $74,43 \%$ & \\
& O-6-10-I & 200 (Sedang) & $24,01 \%$ & \\
& O-6-10-II & 13 (Berat) & $1,56 \%$ & \multirow{2}{*}{833} \\
\multirow{5}{*}{ Kelas Keperawatan } & Kelas 1 & 181 & $21,73 \%$ & \\
& Kelas 2 & 336 & $40,34 \%$ & \\
& Kelas 3 & 316 & $37,94 \%$ & \\
\hline
\end{tabular}

Karakteristik Lama Rawat Inap (length of stay)

Length of stay secara langsung tentunya juga dapat mempengaruhi besarnya biaya yang dikeluarkan untuk persalinan Sectio Caesarea. Semakin lama LOS maka semakin besar pula biaya yang akan dikeluarkan. Oleh karena itu adanya LOS yang melebihi standar tersebut pasti cukup berdampak pada tagihan rumah sakit. Pengelompokan distribusi lama rawat inap pada penelitian ini dapat dilihat pada tabel 4.
Tabel 4. Distribusi Lama Rawat Inap

\begin{tabular}{rcccc}
$\begin{array}{c}\text { Tingkat } \\
\text { keparahan }\end{array}$ & $\begin{array}{c}\sum \\
\text { perawatan } \\
\mathrm{N}=833\end{array}$ & $\begin{array}{c}\text { Rata- } \\
\text { rata }\end{array}$ & $\begin{array}{c}\text { Min } \\
\text { (hari) }\end{array}$ & $\begin{array}{c}\text { Max } \\
\text { (hari) }\end{array}$ \\
\hline O-6-10-I & 620 & 4,3 & 2 & 9 \\
O-6-10-II & 200 & 3,5 & 2 & 12 \\
O-6-10-III & 13 & 5 & 4 & 8 \\
\hline
\end{tabular}

Hasil tabel 4 diperoleh rata -

rata LOS di tingkat keparahan O-610-I (ringan) yaitu 4,3. Tingkat keparahan O-6-10-II (sedang) memiliki rata - rata sedikit lebih tinggi yaitu 4,5 hari, dan pada tingkat keparahan O-6-10-III (berat) adalah 5 hari yaitu yang tertinggi. Hal ini dikarenakan lama rawat inap sangat tergantung dengan kondisi tingkat keparahan pasien tersebut apalagi terjadi komplikasi maka semakin 
Jurnal Insan Farmasi Indonesia, 3(2) Desember 2020 (317-326)

Mochammad Maulidie Alfiannor Saputera

p-ISSN 2621-3184; e-ISSN 2621-4032

doi: 10.36387/jifi.v3i2.599

lama pula pasien akan menjalani hari perawatan.

\section{Biaya Rawat Inap Pasien Sectio Caesarea}

Berdasarkan analisa dan perhitungan data yang diperoleh pada tabel 5 , total antara tarif rumah sakit dengan total klaim INA-CBG's adalah selisih negatif yang dapat diartikan bahwa tarif INA-CBG's tidak bisa mengcover tarif rumah sakit, dengan hasil selisih total sebesar Rp. 3.908.338.992. Agar lebih mudah mengetahui berapa rata-rata biaya tiap pasiennya maka dihitung selisih antara rata-rata biaya tarif rumah sakit dengan ratarata tarif INA-CBG's. Berdasarkan hasil perhitungan, selisih antara ratarata tarif rumah sakit dengan ratarata tarif INA-CBG's adalah Rp 4.691.884 tiap pasiennya. Setelah tiap tingkat keparahan, maka selisih total dan rata-rata biaya tarif rumah sakit dengan tarif INA-CBG's pada tiap kelas perawatannya dapat diketahui lebih rinci.

Berdasarkan hasil perhitungan pada tabel 6 total tarif rumah sakit pada kelas perawatan 2 dengan kode O-6-10-I (ringan)

merupakan total yang tertinggi yaitu sebesar Rp.2.763.236.185 dengan selisih total pada tarif INA-CBG's sebesar Rp.1.209.555.385. Sedangkan kelas perawatan 1 dengan kode O-6-10-III (berat) menjadi biaya yang terendah dengan hasil tarif rumah sakit sebesar Rp. 12.900.000 dengan selisih totalnya pada tarif INA-CBG's yaitu sebesar Rp. 3.703.700.

Selisih total dan rata-rata biaya tarif rumah sakit dengan tarif INA-CBG's pada pasien persalinan Sectio Caesarea di tiap kelas perawatan dapat dilihat pada tabel 5 .

Alasan kenapa total biaya tarif rumah sakit pada kelas perawatan 2 lebih besar dari kelas perawatan 3 karena pasien dari kelas perawatan 2 lebih banyak khususnya di tingkat keparahan ringan dari pada kelas perawatan 3 pada prosedur persalinan Sectio Caesarea peserta JKN di RSD Idaman Banjarbaru tahun 2019. Komponen biaya adalah bagian-bagian dari keseluruhan sehingga terbentuk suatu kesatuan yaitu tarif rumah sakit. Biaya yang dimaksud adalah suatu harga yang harus dikeluarkan 
Jurnal Insan Farmasi Indonesia, 3(2) Desember 2020 (317-326)

Mochammad Maulidie Alfiannor Saputera

p-ISSN 2621-3184; e-ISSN 2621-4032

doi: $10.36387 /$ jifi.v3i2.599

pasien pada saat mendapatkan

perawatan. Komponen biaya pasien

persalinan bedah Sectio Caesarea

sedang dan berat bahwa persentase

komponen biaya yang paling tinggi

adalah pada biaya prosedur bedah.

pada tingkat keparahan ringan,

Tabel 5. Selisih total dan rata-rata tarif rumah sakit dengan tarif INA-CBG's

\begin{tabular}{lcrrrrrr}
\hline $\begin{array}{c}\text { Kelas } \\
\text { perawatan }\end{array}$ & $\begin{array}{c}\text { Tingkat } \\
\text { Keparahan }\end{array}$ & $\begin{array}{c}\text { Total tarif } \\
\text { rumah sakit } \\
(\mathrm{Rp})\end{array}$ & $\begin{array}{c}\text { Rata-rata } \\
(\mathrm{Rp})\end{array}$ & $\begin{array}{c}\text { Total tarif } \\
\text { INA-CBG's } \\
(\mathrm{Rp})\end{array}$ & $\begin{array}{c}\text { Rata-rata } \\
(\mathrm{Rp})\end{array}$ & $\begin{array}{c}\text { Selisih total } \\
(\mathrm{Rp})\end{array}$ & $\begin{array}{c}\text { Selisih } \\
\text { rata-rata } \\
(\mathrm{Rp})\end{array}$ \\
\hline $1(\mathrm{n}=125)$ & & 1.389 .834 .759 & 11.118 .678 & 868.112 .500 & 6.944 .900 & 521.722 .259 & 4.173 .778 \\
$2(\mathrm{n}=261)$ & I & 2.763 .236 .185 & 10.587 .112 & 1.553 .680 .800 & 5.952 .800 & 1.209 .555 .385 & 4.634 .312 \\
$3(\mathrm{n}=234)$ & & 2.269 .013 .328 & 9.696 .638 & 1.160 .803 .800 & 4.960 .700 & 1.108 .209 .528 & 4.735 .938 \\
$1(\mathrm{n}=55)$ & & 646.019 .470 & 11.745 .809 & 403.463 .500 & 7.335 .700 & 242.555 .970 & 4.410 .109 \\
$2(\mathrm{n}=68)$ & \multirow{2}{*}{ II } & 755.996 .408 & 11.117 .594 & 427.563 .600 & 6.287 .700 & 328.432 .808 & 4.829 .894 \\
$3(\mathrm{n}=77)$ & & 810.562 .712 & 10.526 .788 & 403.464 .600 & 5.239 .800 & 407.098 .112 & 5.286 .988 \\
$1(\mathrm{n}=1)$ & & 12.900 .000 & 12.900 .00 & 9.196 .300 & 9.196 .300 & 3.703 .700 & 3.703 .700 \\
$2(\mathrm{n}=7)$ & III & 107.945 .107 & 15.420 .730 & 55.177 .500 & 7.882 .500 & 52.767 .607 & 7.538 .230 \\
$3(\mathrm{n}=5)$ & & 67.137 .623 & 13.427 .525 & 32.844 .000 & 6.568 .800 & 34.293 .623 & 6.858 .725 \\
& & 8.822 .645 .592 & 106.540 .874 & 4.914 .306 .600 & 60.369 .200 & 3.908 .338 .992 & 46.171 .674 \\
\hline
\end{tabular}

Biaya prosedur bedah melibatkan beberapa hal yang menjadikan tingginya biaya tersebut, yang di antaranya adalah biaya Data hasil selisih total prosedur anastesi, prosedur antara biaya tarif rumah sakit pembedahan Sectio Caesarea, prosedur yang melibatkan spesialis anak, dan kebutuhan tambahan seperti ECG monitor dan oksigen $\left(\mathrm{O}_{2}\right)$. dengan tarif INA CBG's dapat dilihat pada tabel 7 .

Tabel 6. Selisih total antara Tarif Rumah Sakit dengan INA CBG's.

\begin{tabular}{crrrc}
\hline Kode INA-CBG's & O-6-10-I (Rp) & O-6-10-II (Rp) & O-6-10-III (Rp) & Total (Rp) \\
\hline Total tarif rumah sakit & 6.422 .084 .272 & 2.212578 .590 & 187.982 .730 & 8.822 .645 .592 \\
Total tarif INA-CBG’s & 3.582 .597 .100 & 1.234 .491 .700 & 97.217 .800 & 4.914 .306 .600 \\
Selisih Tarif (Negatif) & 2.389 .487 & 978.086 .890 & 90.764 .930 & 3.908 .338 .992
\end{tabular}

Berdasarkan hasil pada tabel 6 selisih negatif antara biaya tarif Rumah Sakit dengan tarif INACBG's pada tingkat keparahan I (ringan) sebanyak Rp. 2.839.487.172. Tingkat keparahan
II sebanyak Rp. 978.086.890. dan Tingkat keparahan III sebanyak Rp. 90.764.930. Tarif INA-CBG's pada pasien persalinan Sectio Caesarea tidak mampu menutupi biaya tarif rumah sakit atau selisih negatif 
Jurnal Insan Farmasi Indonesia, 3(2) Desember 2020 (317-326)

Mochammad Maulidie Alfiannor Saputera

p-ISSN 2621-3184; e-ISSN 2621-4032

doi: 10.36387/jifi.v3i2.599

karena berdasarkan data setiap satu kali episode perawatan selalu terdapat hasil negatif dan tidak terdapat sama sekali hasil selisih positif.

\section{KESIMPULAN}

Berdasarkan hasil dari penelitian, maka dapat disimpulkan bahwa biaya tarif rumah sakit dengan tarif INA-CBG's pada pasien persalinan Sectio Caesarea di RSD Idaman Banjarbaru adalah selisih negatif yaitu sebesar Rp.3.908.328.992 (n=833). Dan selisih rata-rata tarif Rumah Sakit dengan rata-rata tarif INA-CBG's adalah Rp.4.691.884 per pasiennya.

\section{DAFTAR PUSTAKA}

1. Aprina dan Puri, A. 2016. Faktor-faktor yang Berhubungan Dengan Persalinan Sectio Caesarea di RSUD DR. H Abdul Moeloek Provinsi Lampung. Jurnal Kesehatan, Volume VII, Nomor 1, E-ISSN 2548-5695

2. Jitowiyono, S. dan Weni Kristiyanasari. 2010. Asuhan Keperawatan Neonatus Dan Anak. Nuha Medika. Cetakan I: Jakarta

3. Gibbson L. et all, 2010. Organisasi, Perilaku, Struktur,

Proses, Edisi Ke-5. Jakarta. Erlangga.

4. Sinha, Kounteya. 2010. Article Times of India. http://ejournal.unsrat.ac.id/index. php/jkp/article/../3568

5. Ayuningtyas, D. Dkk. 2018. Analisis Situasi Kesehatan Mental pada Masyarakat di Indonesia dan Strategi Penanggulangannya. Jurnal Prodi Kesehatan Masyarakat UI. 9 (1). 1-10

6. SDKI. $2017 . \quad$ Badan Kependudukan dan Keluarga Berencana Nasional. Survei Demografi dan Kesehatan Indonesia, Jakarta.

7. Permenkes RI. 2016. Peraturan Menteri Kesehatan No. 64 tentang Standar Tarif Pelayanan Kesehatan dalam Penyelengaraan Program Jaminan Kesehatan.

8. Akbar, 2018. Analisis Perbandingan Biaya Riil Dengan Tarif INA-CBG's Pada Pasien Sectio Caesar di Rumah Sakit Ibu Dan Anak Ibunda Pelaihari. Karya Tulis Ilmiah. Akademi Farmasi ISFI Banjarmasin

9. Depkes RI. 2014. Buku Pegangan Sosialisasi Jaminan Kesehatan Nasional (JKN) dalam Sistem Jaminan Sosial Nasional. Jakarta: Kementerian Kesehatan Indonesia.

10. Salfariani, Intan. 2012. FaktorFaktor Yang Mempengaruhi Ibu Memilih Persalinan Seksio Sesarea Tanpa Indikasi Medis di RSU Bunda Thamrin Medan. Jurnal Keperawatan Klinis, Vol 1 No 1, 2012, pp: 7-12 
Jurnal Insan Farmasi Indonesia, 3(2) Desember 2020 (317-326)

Mochammad Maulidie Alfiannor Saputera

p-ISSN 2621-3184 ; e-ISSN 2621-4032

doi: 10.36387/jifi.v3i2.599

11. Sibuea, MD., Tendean, HMM \&

Wagey, FW. (2013). Persalinan

Pada Usia $\geq 35$ Tahun Di Rsu

Prof. Dr. R. D. Kandou Manado.

Universitas Sam Ratulangi.

Bagian Obstetri Dan Ginekologi

Rsu Prof. Dr. R. D. Kandou

Manado

12. Kementerian kesehatan, 2016,

Peraturan Menteri Kesehatan

Republik Indonesia Nomor 28

Tahun 2014, tentang Pedoman

Pelaksanaan Program Jaminan

Kesehatan Nasional,

Kementerian kesehatan republik

Indonesia, Jakarta. 